\title{
Further evidence of the positive effects of an educational and physical program on headache, neck and shoulder pain in a working community
}

\author{
Franco Mongini - Andrea Evangelista $\cdot$ Eugenia Rota $\cdot$ Luca Ferrero $\cdot$ \\ Alessandro Ugolini - Chantal Milani - Manuela Ceccarelli • Laura Joffrain • \\ Giovannino Ciccone · Claudia Galassi
}

Received: 17 March 2010/Accepted: 30 May 2010/Published online: 20 June 2010

(C) Springer-Verlag 2010

\begin{abstract}
In a controlled trial to evaluate the effectiveness of a simple educational and physical program administered to a large cohort of public servants, we previously found that 6 months following treatment the monthly frequency of headache and neck and shoulder pain and drug intake was reduced by $40 \%$ in the experimental compared with controls. These results were stable at a 12-month follow up. The program consists of brief shoulder and neck exercises to be performed several times a day, a relaxation exercise, and instructions on how to reduce parafunction and hyperfunction of the craniofacial and neck muscles during the day. The purpose of this work was to investigate whether the data previously obtained could be confirmed also in the group of 192 subjects that served as controls in first phase of the study and received the intervention in the second phase of the study. The primary endpoint was the change in frequency of headache and neck and shoulder pain expressed as the number of days per month with pain, and as the proportion of subjects with $\mathrm{a} \geq 50 \%$ reduction of frequency (responder rate) at the last 2 months of the 6-month intervention period compared to the 2 months preceding the intervention (baseline). The number of days of analgesic drug consumption was also recorded. Days per month with headache at the baseline and at the end of intervention period were 6.40 and 4.58
\end{abstract}

F. Mongini $(\varangle) \cdot$ E. Rota $~$ L. Ferrero · A. Ugolini · C. Milani Headache and Facial Pain Unit, Department of Clinical Pathophysiology, University of Turin, Corso Dogliotti 14, 10126 Turin, Italy

e-mail: franco.mongini@unito.it

A. Evangelista - M. Ceccarelli - L. Joffrain - G. Ciccone ·

C. Galassi

Unit of Cancer Epidemiology, CPO-Piemonte,

AOU S. Giovanni Battista, Turin, Italy (mean change $-1.81, p<0.0001$ ), respectively; days with neck and shoulder pain were 7.48 and 6.18 (mean change $-1.30, p=0.0179$ ); days of analgesic consumption were 1.67 and 1.17 (mean change $-0.50, p=0.0222$ ). The responder rate was $42.3 \%$ for headache, $42 \%$ for neck and shoulder pain and $58.3 \%$ for drug consumption. In conclusion, this study adds further evidence on the efficacy of our program and its high acceptability in a large, unselected, working population.

Keywords Headache Migraine $\cdot$ Neck pain . Education · Exercise

\section{Introduction}

Several studies have assessed the efficacy of noninvasive physical management in reducing the frequency of different types of headache and neck pain. However, the weight of the evidence is still limited and the results of recent studies are conflicting and often limited by relatively short follow-up periods [1-9]. In a controlled trial to evaluate the effectiveness of a simple educational and physical program administered to a large cohort of public servants, we found that 6 months following treatment the monthly frequency of headache and neck and shoulder pain was reduced by $40 \%$ in the experimental compared with controls. Moreover, the index of headache or neck and shoulder pain, as well as the frequency of drug intake, was significantly decreased in the treatment group [10]. These results were stable at a 12-month follow up [11].

The purpose of this work was to investigate whether the data previously obtained could be observed also in the group of subjects that served as controls in the first phase of the study and received the intervention subsequently. 


\section{Methods}

The study design of the entire trial according to time flow is reported in Fig. 1. The trial was conducted from March 2005 (month 1) to April 2006 (month 14) and included two phases [10]: during the first phase, an intervention consisting of a physical and educational program was administered to Group 1, while Group 2 served as control. In the second phase, the same intervention was administered to Group 2. Both Groups were followed up to the end of the trial (month 14).

Eligible participants to this study were 192 employees (Group 2) at the peripheral registry offices and the tax office of the City of Turin's registry who belonged to the control group in the first phase of our trial [10].

After informed consent all participants were given a diary for the day-by-day recording of severity (score 0-5) and duration (hours) in that day of their headache and neck and shoulder pain, intake of analgesics (by type) and menstruation days. Diaries were personally distributed and collected each month by the staff or by office members designated as supervisor. Each time particular importance was given to the importance of filling out the diaries during the time period. Diaries were directly filled in by subjects and were automatically processed by an optic reader via a dedicated computer program. Detailed data relative to headache and neck and shoulder pain were collected in a standardized fashion; a psychological assessment according to Axis 1 of the DSM-IV was carried out [12], and a clinical examination that included palpation of pericranial and cervical muscles was performed.

The following diagnoses were made according to the guidelines of the International Classification of Headache
Disorders [13] and the International Association for the Study of Pain [14]: migraine with or without aura (M), tension type headache (TTH), myogenous neck and shoulder pain (MP). Two or more diagnoses in the same subject were possible.

In the first phase of the trial the subjects in Group 2 were asked to keep the diaries for 8 months without receiving instructions. However, they were encouraged by reminding each month that after some time they would also receive the program. At the beginning of month 9, the same intervention as in the previous study [10] was then applied.

The program consists of brief shoulder and neck exercises to be performed several times a day, a relaxation exercise, and instructions on how to reduce parafunction and hyperfunction of the craniofacial and neck muscles during the day. Particular importance was given to the purpose of reducing muscle contraction and to increase the capability of perceiving it when too elevated.

The instructions were as follows

Relaxation exercise (once or twice a day): Sit down in a comfortable armchair in a quiet room. Let your lower jaw drop completely for about 10-15 min. Apply warm pads on your cheeks and shoulders.

Posture exercises: 8-10 times every 2-3 h: (1) Stand upright with your heels, hips, and nape of the neck against a wall. Without moving the rest of your body, bring your shoulders into contact with the wall and release, rhythmically. (2) With your body and head against the wall, make horizontal movements of the head, forwards and backwards. (3) Cup your hands behind your neck. Stretch your head backwards against counterpressure from your hands. Relax after 2-3 s.
Fig. 1 The design of the entire trial according to time flow. Group 2 was the control group in phase 1 (months 1-8) and the study group in phase 2 (months 7-14)

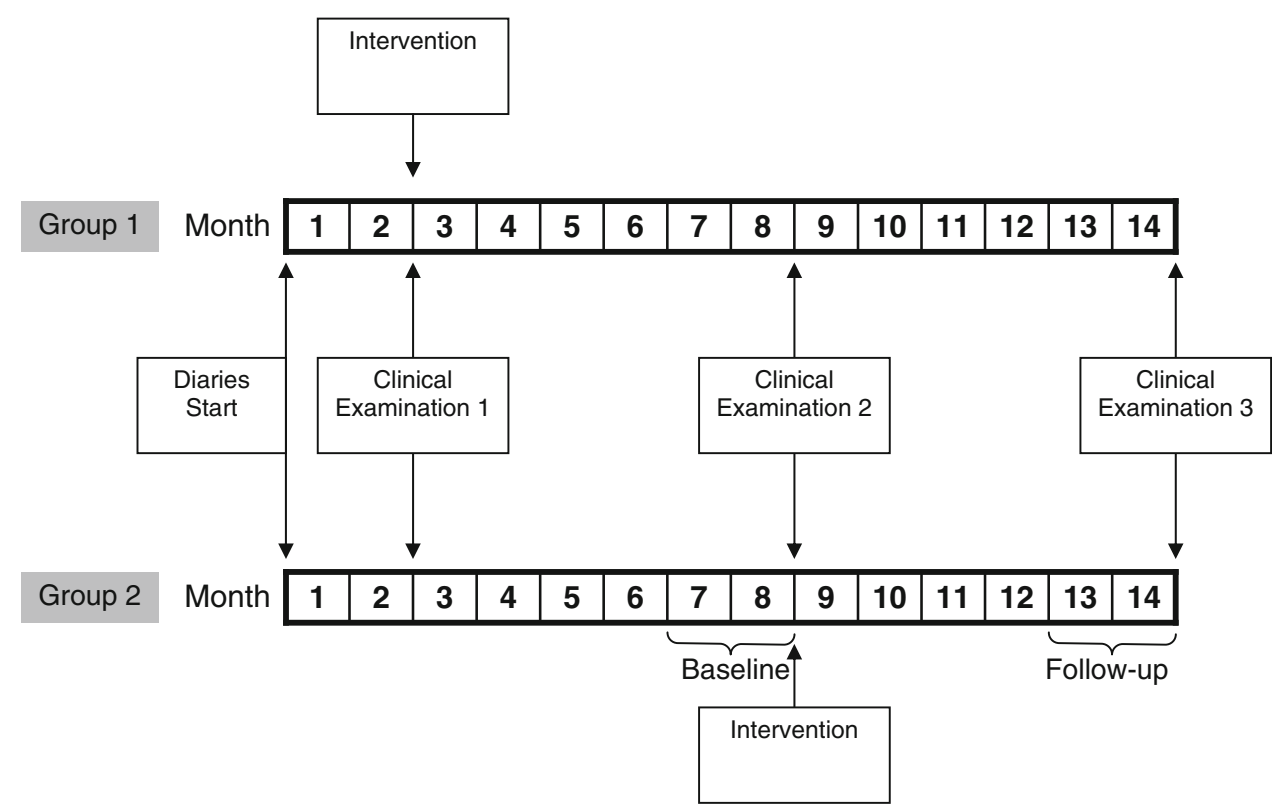


Visual feedback: Place red labels in strategic sites to remind you to avoid excessive contraction of your head and neck muscles.

The instructions were given by the members of the health staff. The program was explained to groups of 30-40 subjects with the help of a short film followed by a practical demonstration and training. The time employed ranged from 45 to $60 \mathrm{~min}$. Red labels were placed on the workplace. Other labels were provided for use at home. A written form was also provided with illustrations on the exercises and the relative instructions. After 2 and 4 months, the instructions were reiterated by the same clinicians at the workplace. Participants continued to fill in their diaries for 6 months after the beginning of the intervention. No indications for a pharmacological treatment were given.

The study was conducted in accordance with the Declaration of Helsinki and the Guidelines for Good Clinical Practice. The protocol was assessed and approved by the Institutional Review Board of the San Giovanni Battista Hospital of the City of Torino. All eligible subjects were asked to provide their informed consent.

\section{Study outcomes}

The primary outcome measurement of the study was the frequency of headache or of neck and shoulder pain (number of days per month with a headache/neck and shoulder pain) after the intervention compared with the data of these variables at the baseline. Two endpoints were used: (1) the frequency of pain at months 13-14 compared to the 2 months preceding the intervention (baseline); (2) the proportion of subjects with 4 or more days per month with headache (neck and shoulder pain) who achieved a $\geq 50 \%$ reduction in pain frequency by months 13-14 (responder rate).

Secondary outcome measurements were the differences in (a) headache or neck and shoulder pain index (intensity $\times$ frequency), where intensity is the sum of intensity of the daily pain in a month divided by number of days with pain; frequency is number of days with pain in a month; (b) frequency of days with analgesic drug consumption.

The Migraine Disability Assessment (MIDAS) questionnaire [15] was also administered at the baseline and at the end of the intervention period. Subjects were asked to record the number of days in the previous 3 months on which they missed paid or household work because of their head or neck pain. Also, they counted the number of days during which their productivity was $<50 \%$ of their normal productivity for both paid and household work. The number of days absent from family, social or leisure activities was also analyzed. The overall MIDAS score is the sum of all these scores and is expressed in terms of number of days. The reliability and internal consistency of the MIDAS were assessed in national and international population-based studies [15-17]. In particular, the MIDAS items for missed days of work or school and for missed days of household work were similar to the corresponding diary-based estimates of missed work or school [17]. The questionnaire's test-retest reliability has been checked in Italian on 109 patients and was closely similar to that found in English-speaking patients [18].

\section{Statistical analyses}

The present study focussed on the 192 subjects included in the Group 2 of the trial (Fig. 1); for 177 subjects diaries were available at months 7-8 (baseline of the second phase of the trial). The principal analysis of the present study was performed on the population of 162 subjects with complete diaries for the second phase of the trial, that is, from months 7-8 (baseline) to months 13-14 (end of follow-up). Baseline differences between subjects with complete diaries and subjects with incomplete diaries were investigated with the use of the chi-square test or Fisher's exact test for categorical variables and with the use the Mann-Whitney test for continuous variables.

The changes from baseline of symptoms frequency (headache, neck/shoulder pain) were evaluated with the Student's paired t-test. The same method was employed in analyzing change from baseline of MIDAS scores.

Responder rates were calculated as the proportion of symptomatic subjects (mean of $\geq 4$ days/month of pain during the baseline period) with a $\geq 50 \%$ reduction in headache days and in neck and shoulder pain days at the end of follow up (months 13-14).

As secondary analysis, we calculated the mean changes in symptom frequency between months 13-14 and months 1-2 (that is, for the entire period of the trial) for subjects with complete diaries included in the Group 2. Thereafter, we compared the mean changes in the symptoms frequency observed in Group 2 with those observed in Group 1 [11]. Due to non-randomized design of this study, mean differences were compared by ANCOVA, adjusting for age, sex, presence of anxiety or mood disorders, frequency symptoms at month 1-2 of each subject, presence of neck and shoulder pain (when the reduction in the frequency of headache and in the use of drug consumption was analyzed), and presence of headache (when the reduction in the frequency of neck and shoulder pain and in the use of drug consumption was analyzed).

Finally, the reduction of the frequency of pain and drug consumption was evaluated by applying longitudinal models to the Group 2 intention-to-treat population 
( $n=192)$, including in the analysis also the data available at each time point for subjects with incomplete diaries, without carrying forward the last value observed. The intention-to-treat analysis using a longitudinal approach allows evaluating the time course of the effect of the intervention during the whole period of the trial. The daily probability of a headache episode during the follow-up was analyzed using a logistic regression model, adjusted for clustering due to repeated measures on the same subject, with the Huber-White sandwich estimators [19]. For all the endpoints studied the effect of time during the follow-up was modeled using a restricted cubic spline function, to allow for potential non-linear trends.

Analyses were performed using STATA 9.2 (STATA Corp., College Station, TX, USA), S-Plus 6.2 (Insightful Corp., Seattle, WA, USA) and with Design and Hmisc program libraries 2 [20].

\section{Results}

Table 1 summarizes the characteristics at the baseline (months 7-8) of subjects included in the principal analysis of the present study, separately for those with complete $(n=162)$ and incomplete $(n=15)$ diaries up to the end of the follow up (months 13-14). No statistically significant differences were found between the groups. However, among subjects with incomplete diaries the prevalence of those with at least 4 days/month with headache, neck or shoulder pain, and consumption of analgesic drugs was higher compared to those with complete diaries. On the other hand, among the 15 subjects with incomplete diaries, 5 reported no headache and 8 reported no neck pain during the last month of recording.

The effects of the intervention for the different end-point examined are summarized in Table 2. For all the endpoints, there was a significant improvement after the intervention.

Mean days per month with headache were 6.40 and 4.58 at the baseline and at the end of follow up respectively, with an absolute reduction of -1.81 (95\% CI -2.54 , $-1.09 ; p<0.0001)$. Mean days with neck and shoulder pain were 7.48 and 6.18, respectively (absolute reduction $-1.30,95 \%$ CI $-2.38,-0.23 ; p=0.0179$ ); mean days of analgesic consumption were 1.67 and 1.17 , respectively, with a reduction of $-0.5(95 \% \mathrm{CI}-0.93,-0.07$; $p=0.0222$ ).

Subgroup analysis showed the following absolute mean reductions: -1.88 (95\% CI $-2.59,-1.17 ; p<0.001)$ for subjects with $\mathrm{M}$ only; $-2.05(95 \%$ CI $-4.12,0.03$; $p=0.053)$ for subjects with TTH only; -3.09 (95\% CI $-4.87,-1.32 ; p=0.001$ ) for subjects having $\mathrm{M}$ and TTH.

For all the outcomes investigated, the reduction in the frequency was more pronounced in the subgroups of subjects with a higher prevalence of disorders at the baseline.

Table 3 shows the proportion of subjects with 4 or more days/month with pain (or drug consumption) during the baseline period who reported $a \geq 50 \%$ decrease or increase in frequency at 6 months. Improved subjects were $42.5 \%$

Table 1 Characteristics of the study population (Group 2) at the baseline (months 7-8) of the second phase of the trial

\begin{tabular}{|c|c|c|c|c|}
\hline & $\begin{array}{l}\text { Complete diaries } \\
(N=162)\end{array}$ & $\begin{array}{l}\text { Incomplete diaries } \\
(N=15)\end{array}$ & $p$ & Total $(n=177)$ \\
\hline Age, median (IQ range) & $44.0(35 ; 49)$ & $45.0(34.5 ; 54.5)$ & 0.549 & $44(35-49)$ \\
\hline Females & $138(85.2 \%)$ & $11(73.3 \%)$ & & $149(84.2 \%)$ \\
\hline Migraine with or without aura $(\mathrm{M})^{\mathrm{a}}$, without TTH & $53(32.7 \%)$ & $4(26.7 \%)$ & 0.777 & $57(32.2 \%)$ \\
\hline Tension type headache $(\mathrm{TTH})^{\mathrm{a}}$, without $\mathrm{M}$ & $41(25.3 \%)$ & $5(33.3 \%)$ & 0.343 & $46(26.0 \%)$ \\
\hline Migraine and TTH & $37(22.8 \%)$ & $3(20.0 \%)$ & 0.548 & $40(22.6 \%)$ \\
\hline Myogenous neck and shoulder pain (MP) ${ }^{\mathrm{a}}$ & $124(76.5 \%)$ & $12(80.0 \%)$ & 0.761 & $136(76.8 \%)$ \\
\hline $\mathrm{M}$ or TTH, without MP & $23(14.20 \%)$ & $1(6.67 \%)$ & 0.580 & $24(13.6 \%)$ \\
\hline MP, without M or TTH & $16(9.88 \%)$ & $1(6.67 \%)$ & 0.565 & $17(9.6 \%)$ \\
\hline $\mathrm{M}$ or $\mathrm{TTH}$, and MP & $108(66.7 \%)$ & $11(73.3 \%)$ & 0.599 & $119(67.2 \%)$ \\
\hline \multicolumn{5}{|l|}{ Subjects with at least 4 days/month ${ }^{\text {b }}$ with: } \\
\hline Headache & $73(45.1 \%)$ & $9(60.0 \%)$ & 0.267 & $82(46.3 \%)$ \\
\hline Neck or shoulder pain & $69(42.6 \%)$ & $9(60.0 \%)$ & 0.194 & $78(44.1 \%)$ \\
\hline Consumption of analgesic drugs & $24(14.8 \%)$ & $3(20.0 \%)$ & 0.705 & $27(15.3 \%)$ \\
\hline GAD and/or Depression (at month 8) & $49(30.2 \%)$ & $7(46.7 \%)$ & 0.191 & $56(31.6 \%)$ \\
\hline
\end{tabular}

Data are presented overall and separately for subjects with and without complete diaries for all months; data are number (\%) if not otherwise indicated

${ }^{\text {a }}$ Diagnosis based on the clinical examination and the diaries at baseline

b Mean monthly frequency during the baseline 
Table 2 Effects of the intervention for the different end-point examined

\begin{tabular}{|c|c|c|c|c|}
\hline & $\begin{array}{l}\text { Baseline } \\
\text { (mean, SD) }\end{array}$ & $\begin{array}{l}\text { Follow-up } \\
\text { (mean, SD) }\end{array}$ & $\begin{array}{l}\text { Within group } \\
\text { difference } \\
\text { (mean, 95\% CI) }\end{array}$ & $p$ \\
\hline \multicolumn{5}{|l|}{ Headache } \\
\hline Days with headache (mean) & $6.4(8.14)$ & $4.58(7.64)$ & $-1.81(-2.54,-1.09)$ & $<0.0001$ \\
\hline $\begin{array}{l}\text { Among subjects with at least } 4 \text { days/month with headache } \\
\text { at baseline }\end{array}$ & $12.49(8.81)$ & $8.62(9.65)$ & $-3.87(-5.20,-2.54)$ & $<0.0001$ \\
\hline Headache Index $(F \times I)$ & $0.45(0.74)$ & $0.32(0.67)$ & $-0.13(-0.19,-0.07)$ & 0.0001 \\
\hline $\begin{array}{l}\text { Among subjects with at least } 4 \text { days/month with headache } \\
\text { at baseline }\end{array}$ & $0.89(0.92)$ & $0.60(0.87)$ & $-0.29(-0.40,-0.18)$ & $<0.0001$ \\
\hline \multicolumn{5}{|l|}{ Neck/shoulder pain } \\
\hline Days with neck/shoulder pain (mean) & $7.48(10.28)$ & $6.18(9.96)$ & $-1.30(-2.38,-0.23)$ & 0.0179 \\
\hline $\begin{array}{l}\text { Among subjects with at least } 4 \text { days/month with neck/shoulder } \\
\text { pain at baseline }\end{array}$ & $16.7(9.88)$ & $12.8(11.39)$ & $-3.93(-5.99,-1.88)$ & 0.0003 \\
\hline Neck/shoulder pain Index $(F \times I)$ & $0.46(0.78)$ & $0.39(0.79)$ & $-0.07(-0.14,-0.01)$ & 0.0280 \\
\hline $\begin{array}{l}\text { Among subjects with at least } 4 \text { days/month with neck/shoulder } \\
\text { pain at baseline }\end{array}$ & $1.04(0.92)$ & $0.84(1.02)$ & $-0.20(-0.34,-0.06)$ & 0.0064 \\
\hline \multicolumn{5}{|l|}{ Analgesic drug consumption } \\
\hline Days with analgesic drug consumption (mean) & $1.67(3.85)$ & $1.17(3.44)$ & $-0.5(-0.93,-0.07)$ & 0.0222 \\
\hline $\begin{array}{l}\text { Among subjects with at least } 4 \text { days/month with analgesic drug } \\
\text { consumption at baseline }\end{array}$ & $8.56(6.42)$ & $5.12(7.53)$ & $-3.44(-6.01,-0.86)$ & 0.0111 \\
\hline
\end{tabular}

Results are based on the subjects for whom diaries for all months (7th to 14th) were available

Table 3 Proportion of subjects with 4 or more days/month with pain (or drug consumption) during the baseline period that had a reduction (Improved) or an increase (Worsened) in pain frequency or drug consumption of $50 \%$ or more at the end of follow-up

\begin{tabular}{lcc}
\hline & $n(\%)$ & $95 \%$ CI \\
\hline Headache (subjects with at least 4 days/month with headache, $n=73)$ & $30.9-54.6$ \\
Improved & $31(42.3)$ & $0.9-11.5$ \\
Worsened & $3(4.11)$ & \\
Neck/shoulder pain (subjects with at least 4 days/month with neck/shoulder pain, $n=69)$ & $30.2-54.5$ \\
Improved & $29(42.0)$ & $4.2-19.8$ \\
Worsened & $7(10.1)$ & $36.6-77.9$ \\
Analgesic drug consumption (subjects with at least 4 days/month with drug consumption, $n=24)$ & $0.1-21.1$ \\
Improved & $14(58.3)$ & $1(4.17)$
\end{tabular}

for headache, $42 \%$ for neck and shoulder pain and $58.3 \%$ for drug consumption).

Table 4 reports the data of the MIDAS questionnaire. An improvement in all the parameters was observed after the intervention, although for the total MIDAS score the difference was not statistically significant.

In a secondary analysis we compared the effect of the intervention during the whole trial period (from months 1-2 to months 13-14) between the two study groups (Group 1 and Group 2). This analysis was based on subjects for whom complete diaries were available for the entire period: $n=156$ in Group 1 [11] and $n=160$ in Group 2. In Group 1 (that is, in the group of subjects that received the intervention during the first phase of the study and was then followed up to month 14), we observed a mean absolute reduction of -2.39 days per month with headache, as previously published [11]. In Group 2, the mean reduction was -1.71 days per month with headache. The adjusted between-groups difference (1.05) was not significant ( $p=0.093$ ). Comparable figures were observed for the other main endpoints: the adjusted between group difference was 1.38 for days with neck/shoulder pain and 0.22 for days with analgesic drug consumption; both these differences were not statistically significant.

Figure 2 shows the results observed with the logistic regression model based on the Group 2 intention to treat 
Table 4 Mean MIDAS scores at the end of months 8 and $14(N=161)$

\begin{tabular}{|c|c|c|c|c|}
\hline & $\begin{array}{l}\text { Baseline } \\
\text { (month 8) }\end{array}$ & $\begin{array}{l}\text { Follow-up } \\
\text { (month 14) }\end{array}$ & $\begin{array}{l}\text { Change between month } 14 \\
\text { and month } 8 \text { (mean, } 95 \% \mathrm{CI})\end{array}$ & $p$ \\
\hline $\begin{array}{l}\text { On how many days in the last } 3 \text { months did you miss } \\
\text { work or school because your headaches? }\end{array}$ & $0.60(2.92)$ & $0.43(1.89)$ & $-0.16(-0.60,0.28)$ & 0.4719 \\
\hline $\begin{array}{l}\text { How many days in the last } 3 \text { months was your } \\
\text { productivity at work or school reduced } \\
\text { by half or more because of your headaches? } \\
\text { (Do not include days you counted in question } 1 \\
\text { where you missed work or school) }\end{array}$ & $2.52(6.01)$ & $1.53(5.71)$ & $-0.99(-2.09,0.11)$ & 0.0776 \\
\hline $\begin{array}{l}\text { On how many days in the last } 3 \text { months did you not } \\
\text { do household work because of your headaches? }\end{array}$ & $1.99(4.91)$ & $1.51(5.94)$ & $-0.48(-1.52,0.56)$ & 0.3649 \\
\hline $\begin{array}{l}\text { How many days in the last } 3 \text { months was your productivity } \\
\text { in household work reduced by half of more because } \\
\text { of your headaches? (Do not include days you counted } \\
\text { in question } 3 \text { where you did not do household work) }\end{array}$ & $2.70(6.91)$ & $1.47(4.01)$ & $-1.23(-2.38,-0.08)$ & 0.0369 \\
\hline $\begin{array}{l}\text { On how many days in the last } 3 \text { months did you miss family, } \\
\text { social or leisure activities because of your headaches? }\end{array}$ & $1.66(4.85)$ & $1.12(5.62)$ & $-0.54(-1.66,0.58)$ & 0.3402 \\
\hline MIDAS total score & $9.47(19.54)$ & $6.07(19.54)$ & $-3.40(-6.83,0.03)$ & 0.0523 \\
\hline
\end{tabular}
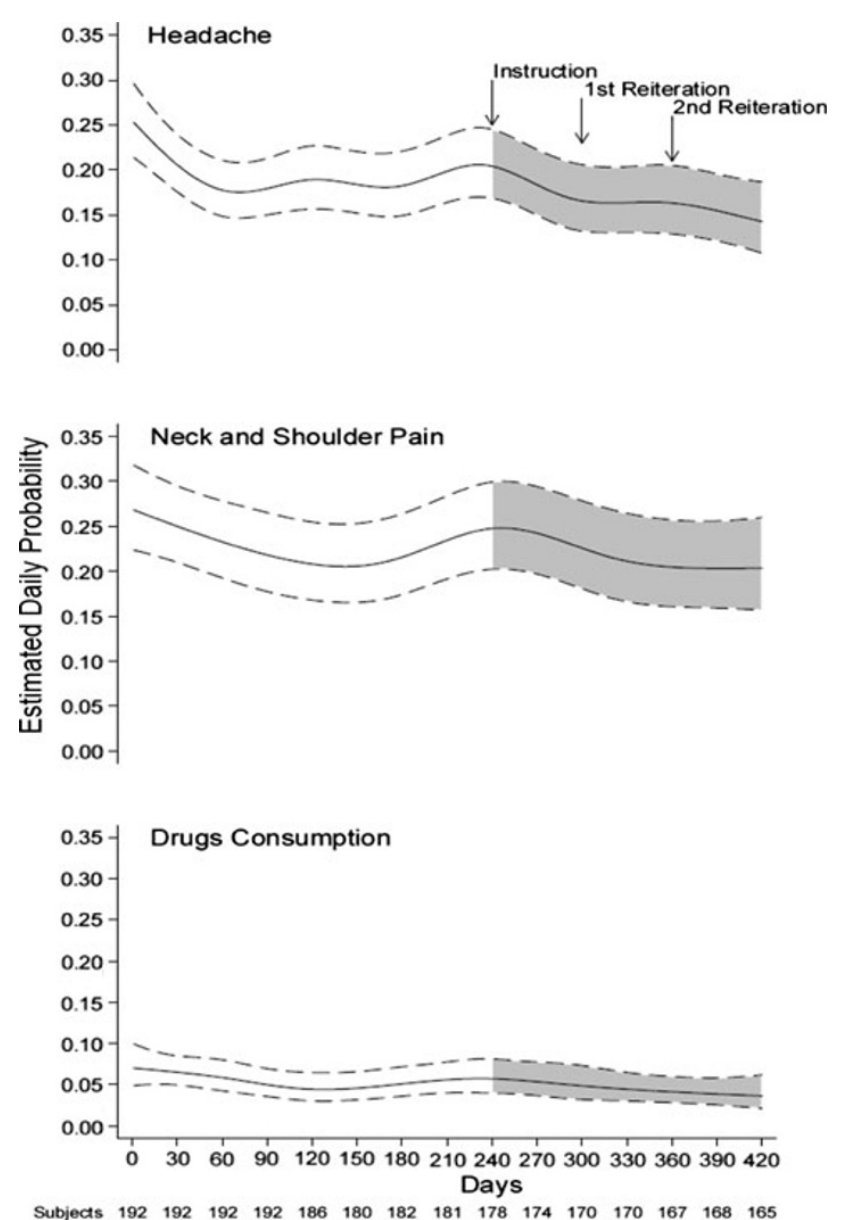

Fig. 2 Reduction in pain frequency and drug consumption during the entire trial period in the Group 2 intention-to-treat population. Results are presented as estimated daily probabilities. The dashed lines indicate the $95 \% \mathrm{CI}$ population $(n=192)$ during the whole study period of the trial (from months 1 to 14). In the first phase of the trial (months 1-8) data for Group 2 were somewhat fluctuating. One reason may be related to the subjects' expectancy, reinforced by keeping a diary. Moreover, a seasonal effect was particularly evident in July-August, when in Italy the climate is warm. The fact that most workers take their holidays in this period may be particularly relevant [10]. However, at the end of the first phase the data tended to the initial values while in the second phase of the trial the improvement was constant along the whole period.

\section{Discussion}

In the control arm of a large non-randomized controlled trial we examined the efficacy of a physical and educational program in reducing headache and neck and shoulder pain. The purpose of this work, that represents a secondary outcome of the trial protocol, was to investigate whether the results previously obtained $[10,11]$ could be confirmed also in the group of subjects that served as controls in the first phase of the study and received the intervention subsequently.

The present data reinforce the evidence of the efficacy of the educational and exercise programme applied. In this group we observed a significant reduction in the frequency of headache and neck and shoulder pain, as well as in the frequency of drug consumption, at the end of the trial compared with the 2 months baseline. The benefit of the intervention was observed also using different analytical approaches. 
The data from the previous studies $[10,11]$ were somewhat better, although not statistically so. The slightly lower benefit observed in the present study may be probably attributed to a seasonal effect. In the previous study the intervention was performed in a warmer period (MayOctober) during which most workers take their holidays as opposed to this study (November-April). Another reason may be the different characteristics of work place and activity of the subjects. Working in a peripheral registry office and in the tax office may indeed be somewhat more stressful than working in the central registry office where, inter alia, there is a more frequent workplace turnover. Nevertheless, the data show that the program is efficacious also in different working conditions.

As mentioned in the previous papers [10, 11], some features of our program are different from the other interventions: in particular, the fact that it may be applied at the workplace may favor a reciprocal reinforcement between the participating subjects. Indeed, when the program was administered, the participants were encouraged to remind each other of keeping the muscle relaxed while working and to perform the exercises together. Such peculiar characteristics may partly explain our better results, compared with some other trials [21, 22].

In conclusion, the moderate but consistent benefit observed in the present study strengthens the evidence of the efficacy of our program and its high acceptability in a large, unselected, working population.

A study with a randomized design on a much higher number of subjects is now in progress in order to confirm that this program can be regarded as an effective way of reducing head and neck pain and analgesic drug consumption in extensive working communities.

Acknowledgments This study was primarily funded by the Compagnia di San Paolo of Torino with additional contributions from the Regione Piemonte.

\section{References}

1. Bronfort G, Nilsson N, Haas M, Evans R, Goldsmith $\mathrm{CH}$, Assendelft WJJ, Bouter LM (2004) Non-invasive physical treatments for chronic/recurrent headache. Cochrane Database Syst Rev 3:CD001878

2. Ghaffari M, Alipour A, Farshad AA, Yensen I, Vingard E (2006) Incidence and recurrence of disabling low back pain and neckshoulder pain. Spine 31:2500-2506

3. Gross AR, Aker PD, Goldsmith CH, Peloso P (1996) Conservative management of mechanical neck disorders. A systematic overview and meta-analysis. Online J Curr Clin Trials Doc No 200-201

4. Gross AR, Aker PD, Goldsmith CH, Peloso P (2000) Patient education for mechanical neck disorders. A systematic overview and meta-analysis. In: Cochrane Library; Issue 4, Update Software, Oxford
5. Kay TM, Gross A, Santaguida PL, Hoving J, Goldsmith C, Bronfort G (2005) Cervical Overview Group. Exercises for mechanical neck disorders. Cochrane Database Syst Rev 3:CD004250

6. Riddle DL, Schappert SM (2007) Volume and characteristics of inpatient and ambulatory medical care for neck pain in the United States: data from three national surveys. Spine 32:132-140

7. Stovner LJ, Zwart JA, Hagen K, Terwindt GM, Pascual J (2006) Epidemiology of headache in Europe. Eur J Neurol 13:333-345

8. Stovner LJ, Hagen K, Jensen R, Katsarava Z, Lipton RB, Scher AI, Steiner TJ, Zwart J-A (2007) The global burden of headache: a documentation of headache prevalence and disability worldwide. Cephalalgia 27:193-210

9. Wiendels NJ, Knuistingh Neven A, Rosendaal FR, Spinhoven P, Zitman FG, Assendelft WJ, Ferrari MD (2006) Chronic frequent headache in the general population: prevalence and associated factors. Cephalalgia 26:1434-1442

10. Mongini F, Ciccone G, Rota E, Ferrero L, Ugolini A, Evangelista A, Ceccarelli M, Galassi C (2008) Effectiveness of an educational and physical programme in reducing headache, neck and shoulder pain: a workplace controlled trial. Cephalalgia 28:541-552

11. Mongini F, Ciccone G, Rota E, Ferrero L, Ugolini A, Evangelista A, Ceccarelli M, Galassi C (2009) Long term benefits of an educational and physical program on headache, and neck and shoulder pain in a working community. J Pain 10:1138-1145

12. Mazzi F, Morosini P, De Girolamo G, Lussetti M, Guaraldi GP (2000) SCID-I-Structured Clinical Interview for DSM-IV Axis I Disorders (Italian Edition). OS-Organizzazioni Speciali, Firenze

13. International Headache Society (2004) The International Classification of Headache Disorders. Cephalalgia 24(Suppl 1):1-160

14. International Association for the Study of Pain (1994) Classification of chronic pain: descriptions of chronic pain syndromes and definitions of pain terms, 2nd edn. IASP Press, Seattle

15. Stewart WF, Lipton RB, Kolodner K, Liberman J, Sawyer J (1999) Reliability of the migraine disability assessment score in population-based sample of headache sufferers. Cephalalgia 19:107-114

16. Stewart WF, Lipton RB, Whyte J, Dowson A, Kolodner K, Liberman JN, Sawyer J (1999) An international study to assess reliability of the Migraine Disability Assessment (MIDAS) score. Neurology 53:988-994

17. Stewart WF, Lipton RB, Kolodner KB, Sawyer J, Lee C, Liberman JN (2000) Validity of the Migraine Disability Assessment (MIDAS) score in comparison to a diary-based measure in a population sample of migraine sufferers. Pain 88:41-52

18. D'Amico D, Mosconi P, Genco S, Usai S, Prudenzano AMP, Grazzi L, Leone M, Puca FM, Bussone G (2001) The Migraine Disability Assessment (MIDAS) questionnaire: translation and reliability of the Italian version. Cephalalgia 21:947-952

19. White H (1980) A heteroskedasticity-consistent covariance matrix estimator and a direct test for heteroskedasticity. Econometrica 48:817-830

20. Azola C, Harrell FE (2001) An introduction to S-Plus and the Hmisc and Design libraries. University of Virginia School of Medicine

21. Sjogren T, Nissinen KJ, Jarvenpaa SK, Ojanen MT, Vanharanta H, Malkia EA (2005) Effects of a workplace physical exercise intervention on the intensity of headache and neck and shoulder symptoms and upper extremity muscular strength of office workers: a cluster randomized controlled cross-over trial. Pain 116:119-128

22. Viljanen M, Malmivaara A, Uitti J, Rinne M, Palmroos $\mathrm{P}$, Laippala P (2003) Effectiveness of dynamic muscle training, relaxation training, or ordinary activity for chronic neck pain: randomised controlled trial. BMJ 327:475-477 